\title{
La moderna ciencia social como indagación sobre el conflicto y la cohesión social*
}

\author{
Modern Social Science as an Inquiry into \\ Social Conflict and Cohesion
}

\author{
Ciências sociais modernas como indagação sobre o \\ conflito e a coesão social
}

Darío Montero**

\begin{abstract}
RESUMEN
El artículo ofrece un amplio cuadro sobre las más influyentes teorías del conflicto y la cohesión social que se han elaborado durante los últimos cinco siglos, como el hegelianismo, el marxismo, el funcionalismo estructuralista, entre otros, con el propósito de enmarcar las discusiones actuales sobre estos fenómenos dentro de las ciencias sociales. Esta revisión general toma la forma de un diálogo con autores representativos de la ciencia social de nuestro siglo XXI, quienes acusan el influjo de una u otra de estas grandes tradiciones teóricas y reevalúan las categorías de 'conflicto' y 'cohesión', a veces enfatizando sus aspectos negativos y, en otras ocasiones, su potencial productivo.
\end{abstract} Palabras clave: ciencia social, cohesión social, conflicto.

\begin{abstract}
The present article offers a broad look at the theories of social conflict and cohesion, which have been developed over the past five centuries, such as Hegelianism, Marxism, Structural functionalism, among others, as the intellectual backdrop against which we can make sense of the current discussions on these phenomena within the social sciences. This general examina-
\end{abstract} Keywords: social science, social cohesion, conflicto.

Este trabajo es una especie de vástago de una labor al interior de la Agenda Teórica del Centro de Estudios de Conflicto y Cohesión Social (COES) entre los años 2014 y 2018 junto a Mauro Basaure. Quiero agradecer al COES y a Mauro, en particular, por esta fructífera colaboración.

** Doctor en Sociología por la Universidad de Jena, Alemania. Académico del Departamento de Sociología de la Universidad de Chile. E-mail: dario.montero@uchile.cl 
tion takes the form of a dialogue with representative 21st-century social scientists, who have been influenced in different ways by those great theoretical traditions and who reassess the categories of "conflict" and "cohesion," either by stressing their negative aspects or by vindicating their productive capacity.

\section{RESUMO}

$\mathrm{O}$ artigo fornece um quadro amplo sobre as mais influentes tePalavras-chave: orias do conflito e da coesão social desenvolvidas nos últimos cinco séculos, tais como o hegelianismo, o marxismo, o estrutural-funcionalismo, entre outras, com o objetivo de enquadrar ciências sociais, coesão social, as discussões atuais sobre estes fenômenos dentro das ciências conflito. sociais. Esta revisão geral toma a forma de um diálogo com autores representativos das ciências sociais de nosso século XXI, os quais acusam a influência de uma ou outra dessas grandes tradições teóricas e reavaliam as categorias de "conflito" e "coesão", às vezes enfatizando seus aspectos negativos e, em outras ocasiões, seu potencial produtivo. 


\section{Introducción}

El libro Investigación y teoría crítica para la sociedad actual, de reciente publicación (Basaure \& Montero, 2018), expone algunas de las corrientes más influyentes del pensamiento social del presente siglo en las palabras de sus propios representantes, pero puede ser leído más específicamente, tal como propongo en este artículo, como una reflexión sobre el conflicto y la cohesión de nuestras sociedades contemporáneas y el modo en que las ciencias sociales han tratado estos fenómenos. Dado que estas cuestiones ocuparon la mente de los filósofos y cientistas sociales desde los comienzos del pensamiento social moderno, y que sus interpretaciones continúan teniendo en muchos sentidos una influencia persistente (como se evidencia en las entrevistas que componen el libro recién aludido), quiero poder aquí ofrecer al lector, a modo de contexto histórico e intelectual, una breve revisión de algunos de los hitos principales de esta reflexión. La relectura de los clásicos del pensamiento social moderno se ensaya, así, desde este punto de vista específico.

El artículo se divide en tres secciones. Una primera que recorre los principales paradigmas filosóficos del conflicto y la cohesión social; una segunda que desgrana los conceptos sociológicos clásicos para comprender los desacuerdos y luchas dentro de las sociedades modernas occidentales, así como los modos en que estas sociedades consiguen mantenerse aglutinadas, resistiendo las tendencias disgregadoras que traen consigo la división del trabajo, la especialización y la individuación, entre otros procesos modernos; finalmente, examino, en una tercera parte, aquellas teorías sociales críticas que han ofrecido en el siglo XX nuevas herramientas teóricas y metodológicas para comprender las dinámicas de conflicto y convivencia social y que permanecen como referentes para el pensamiento social contemporáneo. Esta reconstrucción histórico-conceptual va dialogando con las entrevistas contenidas en el libro que pretendemos comentar, con lo cual el presente artículo toma la forma de un Gelegenheitsschrift, un escrito de ocasión.

\section{Los antecedentes filosófico-políticos: De Maquiavelo a Hegel}

Tal como apunta Charles Taylor, quien cierra la primera parte de esta serie de conversaciones, ya Maquiavelo intuyó que la democracia re- 
quiere "de una cierta lucha de clases... pero dentro de ciertos límites" (Basaure \& Montero, 2018, p. 116). A pesar de su evidente entronque con el republicanismo greco-romano, Maquiavelo se distancia del pensamiento político y social antiguo mediante sus interpretaciones históricas de la Roma republicana, donde presenta bajo una luz muy favorable los tumultos que tuvieron lugar entre plebeyos y patricios tras la caída de los reyes. Las prolongadas discordias que se suscitaron durante aquellos tiempos entre el pololo y el senado romano no solo no despiertan resquemores en el autor de Los Discursos, sino que este las celebra como aquello que finalmente permitió la aparición de la institución popular de los tribunos, algo que, a su vez, garantizó una gran estabilidad a esta república a lo largo del tiempo. Una conclusión normativa para el pensamiento social que se deriva del análisis maquiavélico (o maquiaveliano, como se ha tendido a escribir últimamente) es el abandono de una noción monolítica de bien común - consensus iuris - y el abrazo de una concepción de Estado que tolera y se beneficia de la existencia de, al menos, dos comunidades existiendo y pugnando en su seno. En este respecto, el pensador renacentista toma distancia de los antiguos Aristóteles y Cicerón (incluso de las enseñanzas tomistas sobre derecho natural), quienes asumían que los estados lograban su cohesión en virtud de una unidad moral. Los Discursos de Maquiavelo (2003) —este padre de la ciencia política moderna- se consagra así como uno de los primeros intentos por tomar en serio el significado positivo, tanto histórico como político, del conflicto social.

Con todo, Maquiavelo puede ser considerado una figura bisagra entre el pensamiento antiguo y moderno. Solo en el siglo XVII vemos aparecer en verdad un movimiento intelectual radicalmente nuevo, el que, inspirado por la Revolución científica y un nuevo espíritu de afirmación de la personalidad individual que ya se dejaba sentir durante el Renacimiento, se dedica ahora a sacar las consecuencias teóricas de estos impulsos con miras a la fundación de una nueva ciencia política y social. Para un teórico contractualista del derecho natural como Thomas Hobbes (1992), a quien le tocó vivir una dilatada guerra civil, los seres humanos vivirían naturalmente en un estado de permanente lucha por la existencia, bajo el riesgo de morir de forma violenta en manos de otro, lo que acarrearía la imposibilidad de comerciar y desarrollar la industria, el arte o la ciencia, tal 
como se lee en el famoso capítulo XIII del Leviatán. Solo la instauración de un Estado fuerte, policial - de hecho, un monarca absoluto en la tradición de Carlos I de Inglaterra- sería capaz de poner coto a esta anarquía social. Una visión más optimista de la naturaleza humana nos la ofrece el compatriota y casi contemporáneo de Hobbes, John Locke (1990), para quien el estado prepolítico de la humanidad transcurriría en relativa paz, posibilitándose así las actividades económicas, la propiedad, incluso el poder de resolver, en parte, las disputas humanas. De todos modos, Locke recomienda el paso del estado natural al civil —esta vez bajo la forma de una monarquía parlamentaria, el espíritu que trajo a Guillermo III a ocupar el trono luego de la Revolución Gloriosa- para contrarrestar el potencial de violencia siempre presente en las personas, y que se hace evidente cada vez que se comete un delito como robar o matar. Una sociedad pacífica solo se alcanza realmente cuando los individuos, sirviéndose de su capacidad de cálculo racional, reconocen las ventajas de entrar, vía acuerdo o contrato, a formar parte de una comunidad política arbitrariamente creada, la que se encargaría de producir y mantener la cohesión social. Como se puede apreciar en estas teorías políticas del siglo XVII, el conflicto social se concibe sin más como aquello que debe ser superado para alcanzar una integración pacífica a través del tiempo; entonces, conflicto y cohesión aparecen enfrentados como los extremos de la vida social, siendo esta última noción entendida instrumentalmente con miras a la realización de los individuos y sus planes de vida.

Prosiguiendo el lenguaje contractualista de sus antecesores, pero reaccionando frente a su comprensión puramente instrumental del Estado, Rousseau elabora su propia concepción de orden social en la que se advierte la influencia de la tradición republicana del humanismo cívico que identifica la participación en la comunidad política como un fin deseable de la vida humana. La soberanía se entiende, aquí, como el ejercicio conjunto de la voluntad general de propósitos comunes en tanto y en cuanto las personas sepan dejar de lado sus pequeñas metas egoístas y se eleven a metas racionales-universales. Al entregarse el individuo en cuerpo y alma a la vida política común, asegura con ello su realización humana y su libertad. Aquí la cohesión social es el fin, no el medio. El filósofo del Contrato Social soñó con una democracia utópicamente armónica, en donde esta postulada 'voluntad general' 
resultaría tan obvia que la propuesta de un miembro encontraría el inmediato acuerdo de todos los demás. Pero la expectativa aquí estaría preñada de peligro totalitario, con el consiguiente riesgo para las libertades de los individuos - como han señalado una y otra vez sus críticos. En efecto, para poder superar el estado de competencia y conflicto social propio de la civilización moderna, la teoría de Rousseau (1992) muestra la necesidad de "la enajenación total de cada asociado con todos sus derechos a la comunidad" advirtiendo más adelante, en un giro que se ha vuelto famoso (y ultra citado por sus detractores), que "cualquiera que rehúse a obedecer a la voluntad general será obligado a ello por todo el cuerpo, lo cual no significa otra cosa que se le obligará a ser libre" (pp. 55 y 59$)^{3}$.

De lo anteriormente expuesto se desprenden dos tradiciones contrapuestas del pensamiento social y político moderno. Si en los teóricos ingleses del derecho natural se enfatiza el carácter atomizado y conflictual de las sociedades modernas, en Rousseau se tiende a presuponer una unidad y homogeneidad de las voluntades humanas en torno a la empresa del autogobierno. La primera tradición se ha tendido a perpetuar en las teorías elitistas y económicas de la democracia que, vía Joseph Schumpeter (2015), encuentran sus ramificaciones en las teorías del grupo de interés, en aquellas que describen la vida política como un 'proceso de conversión', así como en varias teorías contemporáneas de la democracia producidas por académicos norteamericanos por otro lado expertos en disciplinas como la economía o las políticas públicas (public policy). ${ }^{4}$ Por el otro lado, la concepción rousseauniana encuentra sus ecos en una interpretación colectivista y participativa de la democracia que se conecta hacia los siglos XIX y XX con una línea marxista-leninista de pensamiento que idealiza, en este caso, algo así como una 'voluntad del proletariado' en pugna contra el sistema de explotación capitalista. El ya citado Charles Taylor, para evitar unilateralismos, se inscribe en una línea intermedia entre estos dos modelos, la que intentaría construir un

\footnotetext{
3 Cabe agregar que Rousseau es considerado como uno de los primeros teóricos en hablar de la pertenencia a una comunidad nacional como un elemento reforzador de la cohesión social.

4 En décadas recientes se ha intentado incluso explicar la teoría hobbesiana del conflicto recurriendo a la teoría de juegos (Taylor, 1987).
} 
tipo ideal de la democracia a partir del rescate de los elementos valiosos de ambos enfoques:

el énfasis en el individuo, el pluralismo y lugar para el disenso que permiten las teorías económicas que descienden de Schumpeter, sin olvidar por el otro lado que en una sana democracia los ciudadanos se han de poder sentir vinculados en algún grado por una solidaridad común, identificarse entre sí en torno a algo significativo para todos. (Montero, 2016, p. 62).

Entre los teóricos del contrato social y Marx, sin embargo, se encuentra Hegel, cuya filosofía política, en particular, ha tenido un enorme y duradero impacto durante los últimos dos siglos en el mundo entero. Comúnmente, a Hegel se lo estudia ya sea por el interés que despiertan sus originales conceptos filosóficos e interpretaciones históricas o como el antecedente filosófico de Marx. Aquí solo revisaremos algunos aspectos de su obra que tienen directa relación con el tema desarrollado en este artículo. En su Filosofía del Derecho, Hegel (1999) distingue famosamente entre el Estado y la sociedad civil (bürgerliche Gesellschaft), esta última abarcando la esfera económica donde rigen relaciones privadas, las necesidades e los intereses particulares de individuos. La división y potencial conflicto de la sociedad civil puede y debe contrarrestarse gracias al universalismo del Estado, el que para Hegel representa el conjunto de las instituciones y prácticas centrales de una sociedad que, al expresar las más altas aspiraciones de los individuos modernos, puede superar los particularismos y legítimamente cohesionar al conjunto de la sociedad. Es evidente que aquí el Estado no resulta de la celebración de un contrato entre individuos autointeresados en pugna, el Estado hobbsiano-lockiano es todavía 'sociedad civil' para Hegel.

Cuando se confunde el Estado con la sociedad civil y es determinado en base a la seguridad y protección personal, el interés del individuo en cuanto tal se ha transformado en el fin último. Este fin es lo que los habría guiado para unirse, de lo que se desprende, además, que ser miembro del Estado corre por cuenta de cada uno. Su relación con el individuo es sin embargo totalmente diferente: por ser el Estado el espíritu objetivo, el individuo solo tiene objetividad, verdad y ética si forma parte de él. La unión como tal es ella misma el fin y el contenido verdadero, y la determinación de los individuos es llevar una vida universal. (Hegel, 1999, p. 371). 
La confianza de Hegel en que el Estado pudiera expresar y, por ende, identificarse con el espíritu de los tiempos descansa en una compleja (y, para el paladar intelectual contemporáneo, implausible) ontología que concibe a la realidad como la manifestación de un orden racional y a la historia como el desarrollo de una consciencia cósmica que va en pos de su autoconsciencia y libertad, pero que requiere del ser humano viviendo en sociedad para su completa realización. El Estado racional y civilizado de su época - post Revolución francesa- restauraría para Hegel la vida ética de las costumbres (Sittlichkeit), las obligaciones morales que las personas tienen para con la comunidad donde viven, sin desconocer la aspiración moderna de autonomía individual, hábilmente teorizada por Kant. Si el ser humano es capaz de reconocer la racionalidad y razón de ser histórica del Estado, entonces se someterá libremente a dicha comunidad. Evidentemente, aquí 'libertad' no connota un capricho personal, el poder hacer lo que se me dé la gana —en sentido de la tradición ilustrada inglesa-, sino que se postula como una libertad positiva de participación en la comunidad superior del Estado en tanto el hombre sigue su propia esencia y razón. Hegel está pensando en una libertad social y concreta (no un mero deber abstracto) que, por ende, supera las contradicciones entre individuo y sociedad. La combinación de estos dos elementos de su pensamiento político explica la dificultad para comentaristas posteriores de clasificar a Hegel en el espectro liberal/conservador.

Según la conocida interpretación contemporánea de Axel Honneth (1997) - quien abre el conjunto de conversaciones del libro que estamos comentando (Basaure \& Montero, 2018)—, para llegar a la concepción de que el Estado racional sintetizaría en una forma histórica superior el impulso moderno hacia la libertad y la antigua concepción comunitaria de la política, el joven Hegel elabora, en los años que pasó en Jena, una teoría del conflicto social que, a diferencia de Maquiavelo y Hobbes, no se reduciría a instintos de autopreservación, sino que estaría fundada sobre impulsos morales. Una lucha entre sujetos por el reconocimiento (Anerkennung) de sus identidades llevaría a través de la historia a la aparición de instituciones y prácticas garantes de la libertad. El movimiento del reconocimiento consiste en una serie de estadios históricos en los que el ser humano, mediante conflicto y reconciliación, va evolucionando a partir de una 
vida moral primitiva hacia una superior que garantice su realización plena. La razón por la cual los individuos no permanecen inmóviles dentro de las relaciones éticas originarias en las que se encuentran, sino que buscan trascenderlas, estriba en la experiencia de que sus identidades no están siendo debidamente reconocidas. La lucha social que se desencadena está así motivada fundamentalmente por conquistar el reconocimiento de sus pares y no por una mera lucha por la existencia.

Hegel, en lugar de una lucha de todos contra todos, comienza su exposición filosófica con las formas elementales del reconocimiento social, que él presenta bajo el título de 'eticidad natural', y solo la violación de esas iniciales relaciones de reconocimiento por distintos tipos de lucha que son expuestos conjuntamente como un estadio intermedio bajo el título de 'delito', llevan desde ahí hasta un estadio de integración social, que formalmente puede conceptualizarse como relación orgánica de eticidad pura. (Honneth, 1997, p. 29).

La idea subyacente aquí es que el pleno florecimiento humano depende de la existencia de relaciones éticas ya consolidadas en la realidad social, como, por ejemplo, relaciones de amor, legales y aquella solidaridad más amplia que Hegel llama Sittlichkeit — todo lo cual solo emerge realmente mediante luchas y conflictos en pos del reconocimiento. A partir de esta idea, Honneth elabora su propio enfoque, el que muestra la importancia de desarrollar la autoconfianza, el autorrespeto y la autoestima en la formación de la identidad humana (y lo perjudicial, por ende, de la humillación o el desprecio). El punto es que estos modos de experimentarse a uno mismo solo pueden ser adquiridos y mantenidos en forma intersubjetiva: a través del reconocimiento de otros seres humanos, a los que yo también reconozco. En consecuencia, dentro de este esquema, la teoría de Honneth se desmarca de los supuestos utilitaristas y atomistas del pensamiento social moderno iniciado con Maquiavelo y Hobbes. Cabe notar que varios de los autores entrevistados para el libro ((Basaure \& Montero, 2018) que da ocasión al presente trabajo, entre ellos, Honneth, Paugam, Lamont y Taylor, han intentado dilucidar las cuestiones del conflicto y la cohesión social desde una perspectiva identitaria o cultural en donde la categoría del reconocimiento juega un rol central. 


\section{Los 'clásicos' del pensamiento sociológico y sus epígonos}

Basándose en un detallado estudio económico sobre las condiciones materiales de las sociedades modernas y sus modos de organización de la producción y el intercambio de bienes, tampoco Marx va a enfocar su análisis de las divisiones y consensos sociales desde una perspectiva individualista, como la contractualista, sino una objetiva o estructural. La división por clases y la consecuente explotación humana y social que se apreciaba en las sociedades noratlánticas del siglo XIX no era creada, según Marx, por tal o cual empresario capitalista en particular, sino por el capitalismo mismo y la posición que cada ser humano ocupa dentro de él. Lo mismo explicaría el aparente consenso que esta sociedad logra establecer entre el capitalista y el trabajador, ese acuerdo básico que consagra el vínculo laboral por el cual el proletario vende 'voluntariamente' su fuerza de trabajo en un mercado. Aquí también sería el sistema y su capacidad de mistificar la relación salarial (cosa de encubrir la explotación que se estaría dando) la causa real a considerar.

Siempre han existido clases, argumentan Marx y Engels (1998) en el Manifiesto comunista, pero dentro de las sociedades capitalistas, la estratificación social se ha simplificado llegando prácticamente al dualismo: los propietarios de los medios de producción, por un lado, y los modernos trabajadores asalariados por el otro, quienes no poseen más que su fuerza de trabajo. El aumento exponencial de las fuerzas productivas gracias al boom tecnológico moderno (la máquina de hilar, el telar mecánico, el martillo movido a vapor) y el impulso propio del sistema capitalista a expandirse constantemente no solo aumenta la explotación sobre el proletariado, sino que incrementa las reservas humanas de esta clase en tanto campesinos, pero también estratos de la burguesía venidos a menos, se convierten progresivamente en mera mano de obra. La consecuente eliminación de las escalas de grises sociales solo contribuye a hacer el conflicto social cada vez más pronunciado, cada vez más blanco y negro, presuponiendo aquí una gran cohesión inter clase. La rigidez del enfoque objetivo-estructural mencionado se dinamiza al considerar la noción de clase no solo como determinada por su posición económica, sino también como un sujeto colectivo que es capaz de vivir y padecer experiencias comunes, 
adquirir mayor conciencia de su destino, tener propósitos y actuar de acuerdo con ellos. La lucha de clases - ya teorizada a su manera por Maquiavelo varios siglos antes- deviene en confrontación política y se ve fortalecida en este proceso ${ }^{5}$. La cohesión identitaria grupal, por ende, también se nutre de este elemento dinámico-agencial. Dentro de este esquema, el Estado moderno (centralizado) está lejos de cumplir una imparcial función cohesionadora e inclusiva de la sociedad, toda vez que aquel se les aparece a los autores de la La ideología alemana (Marx y Engels, 2014) como un órgano coercitivo al servicio de la administración de los asuntos de interés comunes a la burguesía. Junto al aspecto coercitivo, la función consensual del Estado es igual o más peligrosa, por cuanto crearía el espejismo de una comunidad universal de intereses y la defensa de los derechos de todos sus ciudadanos por medio de un lenguaje legalista y abstracto - cuando en verdad solo promueve los intereses de los individuos con propiedad. Como es un instrumento de la clase dominante (una tesis que, sin embargo, Marx mismo contradice al analizar el gobierno francés de Luis Bonaparte en el 18 brumario), la clase trabajadora que aspira a la revolución debe destruir el Estado existente y formar uno nuevo que sea apropiado para asegurar el nuevo sistema de propiedad comunal.

Bajo el capitalismo industrial maduro y la abundancia material acumulada, cree Marx que se puede volver a lograr un control colectivo sobre la producción - el que implica un libre control de la humanidad toda de su destino. En este momento histórico, una clase (el proletariado), luego de una escalada de conflicto societal en el contexto de la creciente pauperización de sus condiciones laborales, desempleo permanente y cíclicas crisis de sobreproducción, hará la revolución con la consiguiente colectivización de los medios de producción y eliminación de la división del trabajo y de las clases sociales, borrando la dicotomía entre dominadores y dominados, un movimiento desde la división del cuerpo social a la recuperación de la unidad. En lo

\footnotetext{
5 De todos modos, al insistir Marx y Engels (2015) en reiteradas ocasiones que las clases son los agentes inconscientes de un proceso histórico propulsado por leyes económicas o al afirmar Engels en el prólogo de la tercera edición del 18 brumario de Luis Bonaparte que "la existencia y, por tanto también, las colisiones de estas clases están a su vez condicionadas por el grado de desarrollo de su situación económica, por el modo de su producción y de su cambio" (p. 217), podría llegar a concluirse que la lucha de clases no constituye en verdad un factor independiente.
} 
fundamental, la nueva sociedad (comunista) no presentará conflictos importantes, una utopía que nos recuerda la concepción rousseauniana arriba expuesta: "El lugar de la antigua sociedad burguesa, con sus clases y antagonismos de clase, será ocupado por una asociación en la que el libre desarrollo de cada uno será la condición del libre desarrollo de todos" (Marx \& Engels, 1998, p. 64). Como se ve, en Marx las dinámicas de conflicto y cohesión social son creadas no por individuos particulares sino por el sistema como un todo.

Reaccionando contra las variantes más deterministas del marxismo, como fueron las teorías materialistas históricas de Kautsky o Plejánov, que marcaron el clima de la Segunda Internacional, Antonio Gramsci propuso posteriormente una lectura más equilibrada de Marx que, inspirada en los escritos políticos de este último, así como en una filosofía de la praxis proveniente de Maquiavelo, enfatiza el poder agencial del ser humano en la historia. Ya que una de nuestras entrevistadas en el libro (Basaure \& Montero, 1998), Chantal Mouffe (1999), incorpora en su reflexión política elementos del pensamiento gramsciano, en tanto pone el énfasis "en la dimensión hegemónica indisociable de las relaciones sociales en la medida en que siempre se las construye según formas asimétricas de poder" (p. 24), valen aquí algunas palabras introductorias sobre este teórico marxista italiano. Contra la esquemática generalización que establece la estructura económica de una sociedad como la real fundación de todo lo que pueda existir en dicha sociedad como vida espiritual, cultural, política, incluso legal - tal como se lee en el famoso Prefacio de la Contribución a la crítica de la economía política (1981)—, Gramsci (2013) abandona la explicación puramente mecánica que predetermina el 'momento' de la revolución para cuando el crecimiento de las fuerzas productivas de una sociedad (básicamente dependientes del desarrollo tecnológico) llegue a tal punto que estas se empiecen a ver frenadas o ahogadas por las estructuras existentes de la sociedad moderna, como son el Estado burocrático, las formas de derecho burgués o la estratificación basada en las actuales relaciones de propiedad. Gramsci, quien fue testigo de cómo, por ejemplo, la Revolución rusa de 1917 se gatilló sin haber fatalistamente esperado el momento prefijado por este materialismo vulgar - era todavía Rusia en aquel entonces una sociedad de rasgos marcadamente feudales exhibiendo signos de un incipiente capitalismo industrial-, se rinde ante la 
evidencia de los hechos epitomizada en la figura voluntarista de Lenin y la revolución que lideran los bolcheviques. De lo que se trata es de entender la acción concertada de seres humanos como un factor relevante del devenir histórico general, así como en la configuración de situaciones de conflicto y cohesión social en particular. Como una fuerza contrahegemónica, el partido comunista debe ganarse a pulso la aceptación de la concepción comunista, construir una voluntad popular. Hegemonía denota aquí el consentimiento que debe lograrse entre las personas en el seno de la sociedad civil — sin descartar el uso de la fuerza, de estrategias coercitivas, cuando las circunstancias así lo pidan. La construcción de consenso ('construcción' pues no puede ser el mero efecto de una constelación de procesos económicos) debe tener lugar tanto a nivel del Estado como de la sociedad civil, tanto mediante tácticas de dominación como de liderazgo intelectual y moral.

Después de la Revolución rusa, el paso de Lenin a Stalin y de este a Brézhnev, el progresivo desmoronamiento interno y la pérdida de legitimidad de los socialismos reales, la aparición de disidentes como Solzhenitsyn y luego Havel, y junto a ellos el despertar de una sociedad civil desde donde brotaban una pluralidad de nuevos movimientos que no se ajustaban al molde antiguo, se hizo demasiado evidente la incapacidad del marxismo como teoría para explicar esta misma fenomenología histórica. Hacia los años 70 del siglo XX, se hablaba dentro de círculos marxistas de una profunda crisis (Althusser, 1978). Varios de nuestros entrevistados recuerdan esta encrucijada de la historia intelectual reciente y cómo la enfrentaron. A propósito de la génesis del libro Hegemonía y estrategia socialista, escrito junto a Ernesto Laclau, Chantal Mouffe relata la crisis de la izquierda a fines de los años 70 , la aparición de los nuevos movimientos sociales post 1968 como el feminismo, el ecologismo y las demandas de la minorías étnicas, que "no eran luchas tradicionales de la clase obrera" y que por lo mismo se tendía "a asimilarlos a la pequeña burguesía y a restarles importancia" (Basaure \& Montero, 2018, p. 121). Del otro lado del Atlántico, el cientista político y sociólogo Sidney Tarrow seguía de cerca la crisis que no dejó tampoco indiferente a la intelectualidad del continente americano. En efecto, el marxismo y el estructuralismo norteamericano experimentaron una crisis en 1968 que, en cierto sentido, decepcionó las expectativas más revolucionarias de la juventud de entonces, por lo 
cual "mucha gente renunció a estudiar movimientos; muchos de nosotros reorientamos nuestros estudios hacia temáticas institucionales. Algunos incluso nos volvimos antimarxistas, como fue el caso - creode varios intelectuales latinoamericanos" (Basaure \& Montero, p. 137). La crisis trajo también una renovación del pensamiento social en distintos flancos. Uno de ellos hace relación con la aparición de la teoría de los nuevos movimientos sociales, el que, dejando atrás los esencialismos de clase y las luchas determinadas por la posición dentro de la estructura económica, enfatizaba un constructivismo más radical y plural para concebir y animar la acción política en democracia.

Pero la crisis teórica del marxismo y sus categorías habla también de una incapacidad para iluminar los cambios en la matriz económica y social de las sociedades occidentales, la que durante las últimas décadas ha sufrido una enorme transformación en su estructura ocupacional. Según Mike Savage, el criterio de clase fue muy importante en Inglaterra hasta los años 50, vale decir, hasta que comenzó un brutal proceso de desindustrialización, en virtud de la cual "hoy el sentido de la división entre clase media y trabajadora se ha vuelto menos evidente, menos central" (Basaure \& Montero, 2018, p. 183-184). Para Savage, sin embargo, la clase todavía existe por cuanto el desafío consiste más bien en estudiarla conscientes del nuevo escenario (neoliberal) y recurriendo a herramientas conceptuales y metodológicas más sofisticadas y complejas. Los nuevos estudios sobre estratificación social buscarían, así, no distinguir a las personas solo en base a un eje económico de desigualdad, sino que también — siguiendo a Bourdieu y sus formas de capital- desde un punto de vista cultural y social.

Estas mismas transformaciones históricas llevaron a otro de nuestros entrevistados, el francés Vincent de Gaulejac, a hablar derechamente del fin de la lucha de clases y su reemplazo por una lucha de posiciones (lutte des places), lo que denotaría un fuerte individualismo prevalente en las sociedades neoliberales occidentales. Las personas en general y, en particular, los segmentos de la población que antes se identificaban con la clase obrera ya no estarían "interesados en cambiar el orden existente, sino más bien en cambiar su propia posición dentro de ese orden - eso es individualismo. Cada individuo contruye su posición en la sociedad" (Basaure y Montero, 2018, p. 280). De Gaulejac es conocido como uno de los principales 
exponentes de la sociología clínica actual, la que busca iluminar los problemas y patologías sociales desde una doble perspectiva: sociológico-estructural y psicológico-subjetiva. Este espíritu interdisciplinario pareciera contradecir las intenciones de uno de los padres de la sociología, Émile Durkheim, en su celo por deslindar a la sociología como ciencia autónoma, con métodos y objetos de estudio propios. Pero se trataría de una contradicción solo en apariencia, ya que en la lectura que nos ofrece de Gaulejac, los textos durkheimianos concederían también una gran importancia "a que los sociólogos tuvieran una formación como psicólogos” (Basaure y Montero, 2018, p. 269). Parece necesario, pues, esbozar en lo esencial los planteamientos de este otro clásico de la sociología.

Prosiguiendo un tipo de análisis social de carácter sistémico, pero enfatizando ahora el aspecto cohesivo —-más que el conflictivo- de las sociedades modernas, el funcionalismo y, en particular, Durkheim corresponden a un importante hito dentro de este bosquejo del desarrollo de las ciencias sociales. El énfasis, además, está puesto mucho más en los procesos de socialización que en una voluntad humana creativa y transformadora. Por último, las influencias de las ciencias naturales y del evolucionismo en biología, vía Comte y luego Spencer, son innegables en el pensamiento de Durkheim (2012). Éste reconoce con toda claridad el proceso de individualización que trae la sociedad industrial moderna, pero en vez de focalizarse en una microsociología de acciones individuales interactuando entre sí, va a dirigir su mirada hacia la nueva estructura forjada: la especialización de las ocupaciones y funciones sociales. Es dentro de esta nueva forma social - su sociología la entiende como una morfología de las sociedades- que la acción individual ha de ser entendida. Se va a hacer notar, a este respecto, cómo la emergencia de nuestras sociedades modernas-occidentales ha traído consigo un debilitamiento de la conciencia colectiva, fundamentalmente de la religión, con su función cohesionadora del todo social. Si antes, en las sociedades primitivas, era la religión (el totemismo, por ejemplo) la que garantizaba la solidaridad social, ahora solo una interdependencia funcional entre individuos especializados puede mantenernos unidos. La división del trabajo remplaza, así a la fuerte conciencia colectiva de antaño. En terminología durkheimiana la solidaridad 'orgánica' reemplaza a la solidaridad 'mecánica'. La estructura segmentada propia de sociedades clánicas y tribales, y basada 
en vínculos consanguíneos e idénticas creencias religiosas, pasa -mediante un proceso de diferenciación social- a una estructura orgánica, donde cada subsistema a modo de órgano cumple con una función diferente y complementaria, con miras al mantenimiento del todo social. En la actualidad no manda tanto el parentesco como la profesión; no tanto las creencias espirituales compartidas, como los contratos, leyes seculares, transacciones comerciales y normas abstractas. Si antes las obligaciones se contraían con el colectivo, ahora se refieren a deberes entre individuos cada vez más conscientes de sus derechos.

No obstante (o precisamente debido a) este declive de la conciencia común, Durkheim cree que es fundamental una regulación moral e institucional de las sociedades modernas, pero puede ocurrir $-\mathrm{y}$ este es, de hecho, el diagnóstico del autor- que la división del trabajo avance demasiado rápido frente a los desarrollos regulatorios. No es un secreto que Durkheim veía con preocupación este desbalance, en contraste con Marx, quien saludaba la intensificación de la división social que se estaba produciendo en la fase industrial del capitalismo moderno. Si para el primero el conflicto socioeconómico se asociaba a un fracaso regulatorio, una suerte de anarquía (por ejemplo, cuando habla de la división del trabajo anómica y/o forzada), el segundo veía en él la anticipación de una transformación social para bien de todos. A diferencia de Marx y los movimientos socialistas de su época, Durkheim no ve la mejora social en términos de cambios económicos, sino morales. La solidaridad orgánica debe ser reforzada mediante la producción de normas morales y derechos, labor en la que deben participar varias instituciones: desde la escuela (laicas y confesionales) hasta el Estado republicano, pasando por la familia nuclear moderna. Se trata de reducir la anomia mostrando la impotencia de normar los deseos e interacciones humanas. Continuando el uso de un lenguaje naturalista, ahora en clave médica, Durkheim va a distinguir formas sociales normales y patológicas, y va a tender a ver ciertos aspectos característicos de la sociedad moderna - tales como las situaciones de anomia o falta de regulación, o incluso las situaciones de conflicto social-como patológicos y, por ende, disfuncionales para el todo social.

En Durkheim se observan las raíces de las escuelas estructuro-funcionalistas que alcanzan su apogeo a mediados del siglo XX con las obras de Talcott Parsons (1968) y Robert Merton (1964), quienes enfa- 
tizan la importancia de las normas morales en su capacidad de regular y disciplinar los impulsos humanos. El naturalismo también se perpetúa; las estructuras sociales se distinguen también entre normales y patológicas. Pareciera que el llamado de estos autores es a retornar a un estado de orden o equilibrio social, erradicando las prácticas o conductas conflictivas que escapen o atenten contra el marco regulatorio de las sociedades modernas occidentales. Una serie de eventos históricos, sin embargo, hicieron cuestionar en parte la pertinencia de esta sociología sistémica norteamericana. Piénsese, por ejemplo, en la guerra de Vietnam, en donde un país pequeño y subdesarrollado desafía a una potencia sistémica como Estados Unidos y, en cierto sentido, la derrota; en los movimientos por los derechos civiles, que también desestabilizan el equilibrio de esta sociedad, ahora desde adentro; o, por último en la revolución estudiantil de Paris del 68. Una nueva teoría social con énfasis en el conflicto reemerge en torno a esos años, como veremos más adelante. Pero a pesar del declive que a partir de los años sesenta del siglo XX ha sufrido el estructuralismo funcional como corriente, la figura de Durkheim no ha perdido vigencia. Autores tan diversos como Pierre Bourdieu, Anthony Giddens, Niklas Luhmann o Steven Lukes han incorporado en sus trabajos tesis y categorías durkheimianas. Tal como lo señala el sociólogo francés Serge Paugam, incluido en la compilación de entrevistas que estamos revisando (Basaure \& Montero, 2018), la influencia de este padre fundador de la sociología continúa viva en la academia.

Otro influyente punto de partida que retoma una corriente más liberal e individualista, y que sigue alimentando la discusión actual sobre el conflicto y la cohesión social, se encuentra en la obra de Max Weber. Su libro $L a$ ética protestante y el espíritu del capitalismo se suele interpretar como una respuesta radicalmente opuesta a la explicación economicista de la modernidad ofrecida por Marx, por cuanto Weber mostraría allí el impulso crucial dado por la religión protestante en la constitución de la sociedad capitalista moderna (Weber, 1998). Pero el contraste entre ambos autores no es tan unilateral y burdo como parece. Tal como nos recuerda Taylor, en la entrevista ya aludida:

Los críticos usualmente caen muy por debajo del nivel de sofisticación de Weber. Él no dijo: no importó nada más. Él dijo: por supuesto que hay sistema de contabilidad de partida doble, lo cual es una 
condición muy importante para el trasfondo del giro hacia otro tipo de capitalismo; pero él incorpora las aspiraciones religiosas de tipo patrióticas. (Basaure \& Montero, 2018, p. 110).

En efecto, con Weber la atención está fundamentalmente puesta, sin descartar los factores económicos, en las dimensiones culturales y políticas de las sociedades que estudia. ¿Cómo se puede mantener una comunidad humana cohesionada? Para responder esta pregunta habría aquí que repasar la teoría weberiana de la legitimidad y de la dominación.

Si en sociedades premodernas las fuentes de la legitimidad (y por ende de obediencia voluntaria) provenían de la tradición - la creencia en la bondad de modos de actuar inmemoriales- y de las cualidades personales de un líder extraordinario (carisma), lo que mantiene unidas y hace viables a las sociedades modernas es la creencia de las personas en reglas racionalmente establecidas de acuerdo con procedimientos formales. En principio, lo que aquí se está afirmando es que la autoridad del presidente de una república moderna, o del gerente general de una empresa capitalista, no descansaría en la legitimidad de un linaje familiar o en atributos personales carismáticos sino, por sobre todo, atendiendo al modo (procedimiento correcto), en que obtuvo su puesto y las reglas o estatutos previamente acordadas que le dictan y limitan su poder de acción. El burócrata es el tipo puro de este modelo formal-legal de legitimidad. Pero Weber no descarta la posibilidad del carisma bajo condiciones modernas. Al contrario, en la (re)aparición de políticos carismáticos ve este sociólogo alemán la única posibilidad de contrarrestar la impersonalización, atomización y demás consecuencias negativas de la creciente racionalización y burocratización de la cultura moderna ${ }^{6}$. Estas formas de autoridad legítimas no están, sin embargo, desvinculadas del elemento del poder y del uso de la violencia, por lo que Weber las entiende al mismo tiempo como formas de dominación. El líder debe mandar, dominar, y esto

\footnotetext{
6 Quizás no está de más apuntar aquí brevemente -para evitar caer en una interpretación demasiado unilateral de este autor-que, junto a estos individuos carismáticos, Weber considera asimismo a la comunidad lingüística y cultural que identificamos con la nación como otro fundamental recurso disponible para fortalecer la cohesión social de las sociedades modernas. La religión es obviamente otra fuente histórica de solidaridad, pero ésta en el análisis weberiano se ve progresivamente debilitada ante el imparable proceso generalizado de racionalización de todas las esferas de la vida.
} 
siempre estará respaldado por la amenaza de servirse de la violencia, pero para que esta autoridad funcione, es decir, que la gente la obedezca de buena gana, dicha dominación ha de estar legitimada, ha de encontrar un estrecho vínculo con las creencias, valores y motivaciones compartidas por la comunidad sobre la que se ejerce esta influencia. Así, en su famosa definición de Estado, "Estado es aquella comunidad humana que, dentro de un determinado territorio (el 'territorio' es elemento distintivo), reclama (con éxito) para sí el monopolio de la violencia física legítima" (Weber, 2001, p. 83).

Bajo condiciones racionales-formales, el Estado burocrático tiene en los hechos una enorme capacidad para cohesionar la sociedad que rige en defensa exterior, produciendo y protegiendo la ley y los derechos de sus ciudadanos, proveyendo seguridad social y reforzando los lazos de solidaridad culturales de la nación sobre la que se asienta. El elemento burocrático, especializado y reglado permite una administración eficiente y coordinada del sistema social, garantizando, así, su coherencia bajo condiciones de alta complejidad. En este contexto, el pesimismo (o realismo) weberiano terminará reconociendo la inevitabilidad del elitismo en política. Esta intuición probablemente se encuentre desarrollada con más vigor y en forma más explícita en los escritos de su amigo Robert Michels (2008). La ecuación que establece este último es sencilla: el tamaño y complejidad de las democracias modernas hace necesario el desarrollo de inmensas capacidades organizacionales bajo la forma, por ejemplo, de partidos de masas, pero estas mismas capacidades organizacionales-burocráticas, que requieren de especialización técnica, conducen finalmente a que el poder se concentre en pocas personas, en una reducida clase política profesional. "La organización implica la tendencia a la oligarquía" (Michels, 2008, p. 79). Tanto en Weber como en Michels se advierte la constatación - con toques de pesimismo, ironía y hasta cinismo- de que gobernar es siempre un asunto de elites. (Es en este punto donde los nombres de Weber y Schumpeter, tan opuestos en otros sentidos, se aproximan en teoría política).

En suma, la sociología weberiana comienza con individuos y grupos que interactúan y compiten entre sí —no solo por intereses económicos, sino también por estilos de vida, estatus y otros recursos inmateriales- hasta que, en el juego político, esta competencia 
se trasfiere o delega hacia elites de políticos profesionales, de modo que estos se disputen entre sí los puestos en la administración del poder estatal, siguiendo procesos y reglas imparciales y razonables. Los poderes que cohesionan a las sociedades modernas son las mismas 'jaulas de hierro' que oprimen y alienan a los individuos, sin desconocer que, por el otro lado, la aparición de liderazgos políticos pueden, hasta cierto punto, contrarrestar los efectos contraproducentes de la racionalización, inspirando a las personas, reencantando un mundo crecientemente desencantado e impersonal. Muchas de las corrientes vistas hasta aquí están presentes en los trabajos del cientista político Daniel Gaxie, con quien conversamos sobre sus influencias iniciales que lo condujeron finalmente a sus estudios sobre militantismo, así como sobre el mercado y la competencia política: "Comencé a leer mucho a Weber, volví sobre Marx, descubrí Schumpeter, y leí sin mucha utilidad a todos los maquiavelistas, a todos los elitistas: Pareto, Mosca, Michels" (Basaure \& Montero, 2018, p. 151). De todos modos, una de las influencias más directas y fecundas sobre Gaxie será la ejercida por el sociólogo Pierre Bourdieu, como veremos más adelante en este artículo. También Hans Joas - otro de los entrevistados en el libro- hace explícita las influencias de la sociología clásica sobre sí, sosteniendo que su manera de pensar la cohesión social está menos influida por Durkheim que por Weber. Joas, por ejemplo, no cree que los valores compartidos sean la base de la cohesión social sino que, sin desconocer el rol de los valores, han de poder reunirse otras condiciones más 'duras' como la bonanza económica de una sociedad, una percepción de que la comunidad es justa y el sentimiento de seguridad interior y exterior.

Georg Simmel (2010), sociólogo alemán, contemporáneo exacto de Weber y amigo suyo, propone de entrada en su célebre ensayo sobre el conflicto, de un modo llano, su visión particular sobre este fenómeno:

Al igual que el cosmos, para tener forma, necesita 'amor y odio', fuerzas de atracción y de repulsión, la sociedad necesita un combinado de armonía y disonancia, de asociación y lucha, de simpatía y antipatía para definir su forma. Y estos binomios en modo alguno son meros pasivos sociológicos, factores negativos, que la sociedad habría de superar para poder existir; la sociedad es, efectivamente, el resultado de la interacción entre las dos categorías. Es decir, tanto 
las tendencias unitarias como las disgregadoras son constitutivas de la sociedad y, en este sentido, son positivas. (p. 19).

El conflicto representa para Simmel un elemento positivo, formativo de lo social. Cualquier formación social requiere, junto con las fuerzas asociativas, aquellas del conflicto. No se trata de que haya un factor destructivo y otro constructivo, los que, juntos, anulándose mutuamente, dieran como resultado a la sociedad. La unidad social en la que piensa Simmel es de tal naturaleza que contiene ella misma en forma constitutiva el momento del antagonismo, lo que separa, lo dual. Lo que se quiere destacar es, pues, la función integradora del conflicto. Se ofrecen en este sentido tres ejemplos: la competencia económica, los desacuerdos y las discusiones matrimoniales, y el sistema social indio, aquel que "no descansa solo en la jerarquía de las castas sino, también, en su mutua repulsión” (Simmel, 2010, p. 20). La oposición nos permite también afirmarnos como individuos, incluso darnos satisfacción. Esta última idea, junto al ejemplo del matrimonio, nos demuestra que Simmel está pensando en situaciones tanto macro como microsociales y psíquicas. El sentimiento de antipatía, por ejemplo, puede hacernos más llevable la vida en una gran ciudad, generando esa necesaria distancia para con las demás personas y múltiples impresiones que la vida urbana depara. El conflicto es, así, un factor de socialización y solo pierde este carácter en el caso límite del exterminio, el acto de dar muerte a otra persona. El resto de los antagonismos, donde interviene siquiera la más mínima consideración del otro, es formativo. Incluso la esclavitud constituye, para este pensador, un vínculo sociológico que puede tener efectos atenuadores en la hostilidad. Otro caso, solo aparentemente extremo o unilateral, parece ser, según deja entrever Simmel, el de moralistas escépticos como Hobbes (y el de menos escépticos, como Locke o Adam Smith), para quienes existiría una 'enemistad natural' entre los seres humanos, pero, en verdad, este impulso egoísta siempre viene acompañado de motivaciones más empáticas, las que conjuntamente conforman nuestras relaciones sociales. Simmel (2010) habla en el mismo ensayo de una pulsión antagonista como atributo del alma humana junto con la simpatía, aunque la explica como el resultado de un proceso de decantación histórica de guerras y conflictos por causas materiales. Frente a un conflicto objetivo dado, la rabia o el odio pueden ser un buen complemento subjetivo, en tanto ofrecen una cierta determinación o fuerza para hacer triunfar a un 
individuo o grupo. Estas pulsiones surgen, por ende, como "capacidad interna de adaptación" (Simmel, 2010, p. 32) frente a interacciones humanas.

\section{Las teorías del conflicto y de la cohesión en el siglo $\mathrm{XX}$}

La teoría del conflicto de Simmel es rica en detalles, entre los que destacan: análisis sobre los celos y la envidia, la competencia, el socialismo moderno o los gremios del medioevo, y ha estimulado a un sinnúmero de cientistas sociales posteriores a expandir sus reflexiones en distintas direcciones. A mediados del siglo XX, bajo la influencia de Marx, Simmel y otros, se elaboró una teoría del conflicto, en tanto sociólogos como Lewis Coser $(1956,1967)$ y Ralf Dahrendorf (1959, 1968) criticaron el paradigma funcionalista estructural dominante por la excesiva importancia concedida al aspecto consensual y carente de conflictos de las sociedades. También, Charles Wright Mills (1956, 1959) se distancia de la teoría estructural funcionalista de Parsons por carecer, en su opinión, de una perspectiva crítica, haciendo al mismo tiempo aportes decisivos a la teoría del conflicto, argumentando, por ejemplo, cómo la formación y división de la sociedad norteamericana se encuentra condicionada por los vínculos entre los poderosos y las personas sin poder.

Por otro lado, las tesis revisadas de Marx y Weber se complementan provechosamente de los trabajos de Theodor Adorno, Max Horkheimer (1998) y el resto de los teóricos críticos que se agruparon en Frankfurt en torno al Institut für Sozialforschung en el período entreguerras. Para esta corriente, la dominación, cohesión y reproducción de las sociedades occidentales (con la consecuente alienación de los sujetos) no descansa solo en el sistema capitalista imperante, sino que también en las esferas políticas y culturales de la sociedad. En todas ellas alienta una racionalidad instrumental y un deseo de control al tiempo que los seres humanos se van adormeciendo y perdiendo sus facultades críticas a expensas de la pérdida de su libertad. Junto al Estado y la familia, la industria cultural y del entretenimiento, como el cine, por ejemplo, contribuyen a controlar y cohesionar al cuerpo social. Los teóricos de Frankfurt le enrostran a Durkheim y al estructuralismo funcional que, en su búsqueda de cohesión social, su sociología solo termina justi- 
ficando y reproduciendo el orden social existente y la opresión concomitante ${ }^{7}$. Famosa ha devenido también la contradicción explicitada por los teóricos de Frankurt entre la promesa liberadora de la Ilustración y la razón en contraste con la dominación y opresión humana que ella trae. Autores contemporáneos, como Hartmut Rosa, otro de los entrevistados del libro y quien se inscribe en la tradición de la Teoría Crítica, reactualizan esta tesis de la contradicción en su teoría de la aceleración y estabilización dinámica de las sociedades actuales de un modo igualmente sugerente, aunque con un matiz diferente. Basta con decir aquí que, por estabilización dinámica, Rosa quiere entender ese rasgo peculiar de la sociedad moderna en virtud del cual sentimos la presión de acelerar y crecer constantemente con el fin de simplemente mantenernos en el lugar donde nos encontramos, evitando caer. Debido a esta 'jaula de hierro' de la modernidad,

el sujeto moderno se ve forzado a invertir su creatividad, su personalidad, sus aspiraciones y deseos, cosa de hacerlos vendibles y así tener éxito en la búsqueda de capital económico, cultural, social y corporal. Así las cosas, no somos en realidad libres sino que esclavos de la autonomía, si se me permite la expresión". (Basaure \& Montero, 2018, p. 68).

Cabe agregar que Rosa (2005) ha ofrecido una sugerente nueva teoría del conflicto que comprende a las sociedades contemporáneas como sociedades aceleradas en todas sus esferas sociales, pero como no todas las esferas se aceleran de la misma manera, se producen conflictos y tensiones internas, lo que él llama crisis de desincronización. Tómese como ejemplo la rapidez de la esfera económica, en especial de la economía financiera-especulativa, frente a la lentitud de los procesos político-democráticos que requieren de deliberación y consensos, cada vez más difíciles de alcanzar.

Es cierto que es posible visualizar un vínculo entre Weber, la primera Escuela de Frankfurt y Michel Foucault - sus teorías de la dominación, la atención puesta sobre el entramado de prácticas discipli-

Cabe mencionar en este punto que, en su entrevista, Serge Paugam rechaza la visión de Durkheim como un conservador que no supo plantear el tema del conflicto, agregando que "[é]l no era un conservador: para su época fue un progresista, un defensor de las instituciones republicanas francesas y de los derechos humanos" (Basaure \& Montero, 2018, p. 177). 
nantes modernas y el diagnóstico pesimista-, pero la comprensión del poder que ofrece el último Foucault (1980) marca una diferencia que conviene brevemente consignar. La observación es la siguiente: si antes el poder se manifestaba en el espacio público y a través de una autoridad pública, por ejemplo, el rey, ahora el poder opera bajo la forma de una vigilancia universal. En las tecnologías de control modernas - presentes en cárceles, hospitales, colegios y cuarteles, y que moldean la identidad del individuo moderno- se manifiesta un otro tipo de poder, que tiene tres rasgos. Primero, no interesa la ley, sino la normalización (lo desviado tiene que rehabilitarse de acuerdo a un estándar de lo normal); segundo, lo moderno no prohíbe o limita, sino que produce o forma al nuevo individuo o sujeto y las nuevas conductas esperadas; finalmente, el poder no está ejercido por un sujeto o asamblea en particular, sino que es una compleja organización omniabarcante y descentrada. Los interesantes análisis de Foucault, que hablan de un poder de control y cohesión oculto y generalizado que opera a través de técnicas y procedimientos, hacen aparecer a los teóricos críticos anteriores algo ingenuos con su denuncia del Estado o la industria cultural, instituciones y prácticas que, por decirlo así, se pueden apuntar con el dedo. El Estado mismo, para Foucault, no ha de entenderse como una institución centralizada, sino como algo que actúa sirviéndose de complejas redes de poder que afectan al cuerpo de los ciudadanos, la vida sexual, la familia, el conocimiento, la tecnología, etcétera. El punto no está en la soberanía estatal sino las relaciones de poder de base. Es lo que Foucault (1999) desarrolló desde fines de los años setenta bajo el concepto de gubernamentalidad. Foucault ha influido directamente sobre algunos de nuestros entrevistados, como es el caso de Chantal Mouffe, Vincent de Gaulejac o Will Davies.

Dentro de la segunda generación de la Escuela de Frankfurt destacan las reflexiones de Jürgen Habermas (2010), quien, superando el pesimismo weberiano de la primera generación, pone una nota de optimismo al identificar nuevas instituciones y oportunidades que inaugura la sociedad ilustrada con la emergencia histórica, desde el siglo XVIII, de una esfera pública, garantías legales para los ciudadanos y la posibilidad de un libre debate de ideas entre personas iguales en dignidad y derechos — un novum de la modernidad. En sintonía con el giro lingüístico que experimentaron la filosofía y las ciencias 
sociales durante el siglo $\mathrm{XX}$, los aspectos culturales nuevamente destacan en este enfoque contra el énfasis marxiano sobre la economía y el modo de producción: la integración social aquí está basada en prácticas comunicativas entre sujetos racionales. No es que ignore los efectos perjudiciales sobre la racionalidad comunicativa del capitalismo y la industria cultural (en el sentido de Adorno y Horkheimer), pero su diagnóstico final es esperanzador. El proyecto moderno vale la pena llevarlo hasta sus últimas consecuencias. El conflicto social, cultural o político tiende a verse subestimado a favor del énfasis que Habermas le da a la construcción de consensos entre individuos o grupos humanos racionales. Es este aspecto en particular del pensamiento habermasiano el que Chantal Mouffe va a desafiar con su concepción agonística de la democracia, como da testimonio la entrevista incluida en el libro que estamos analizando. Para esta teórica política belga, el espacio político y democrático es una arena de luchas entre proyectos colectivos inconmensurables entre sí. Es más, la única manera de evitar guerras y el puro uso de la fuerza, así como la aparición de movimientos culturales y políticos extremistas, es precisamente permitiendo la expresión de un conflicto dentro de ciertos límites. Otra diferencia importante con Habermas tiene relación con el universalismo que promete su razón comunicativa, por cuanto Mouffe propone "una visión contextualista de las cosas" que no cree que "el modelo occidental de democracia sea el más racional o el más moral" (Basaure \& Montero, 2018, p. 130).

En otro sentido, Charles Taylor toma distancia respecto a su contemporáneo Habermas por defender este último lo que el filósofo canadiense llamaría una doctrina de principio único, que pretende reducir toda la vida moral humana a un solo principio: a lo racional que funda normas correctas o justas, pero esto no permitiría dar cuenta de la riqueza del obrar humano ni de cómo la moral realmente se desarrolla en la práctica. Los habermasianos "hacen una clara distinción entre la ética y la moral. Estrictamente, no se pueden separar, y uno no puede simplemente sustraer una de ellas y decir: eso es suficiente" (Basaure \& Montero, 2018, p. 108). Taylor, por su parte, pone la cuestión del buen vivir en el centro de su filosofía social y política. Lo que a este le interesa investigar y hacer explícito son precisamente las concepciones de la vida buena de las personas: las aspiraciones y motivaciones gracias a las cuales la gente evalúa el mundo en que vive y actúa dentro 
de él. A partir de un conjunto de motivos y valoraciones compartidas es que Taylor (1983) se propone dar cuenta de lo que ha permitido mantener cohesionada a las sociedades europeas y americanas modernas durante los últimos siglos y que estaría basado en "la identidad del hombre como productor, es decir, un ser capaz de transformar la sociedad para sus fines, y más aún, de dedicarse a una transformación de envergadura cada vez mayor" mediante "la combinación de tecnología y colaboración social” (p. 244). Esta sociedad de productores, sin embargo, fue puesta en cuestión una vez que un número creciente de personas se fueron dando cuenta "del costo del crecimiento en materia de contaminación, sobrepoblación, dislocación social y la inminente amenaza de graves limitaciones al desarrollo" (p. 246); pero también esta visión societal fue desafiada en base a una autocomprensión alternativa del ser humano de corte romántico-expresivista, la que se encuentra teorizada en los escritos de Herder, Schiller, Hegel o Marx - y que en el terreno histórico-político ha inspirado a una serie de movimientos antisistémicos como, por ejemplo, las revueltas de mayo del 68, las que marcaron (o coincidieron con) el inicio de un período de crisis de la modernidad occidental. La crisis económica y política de los países industrializados durante los años 70 y 80 la analizó Taylor (1985) desde esta perspectiva culturalista en su famoso artículo Legitimation crisis? Como se puede apreciar en la entrevista con Taylor, la noción de 'imaginario social' ha sido utilizada por este autor en años recientes para iluminar las autocomprensiones compartidas, y en gran medida implícitas, que cohesionan a una comunidad política. Dentro del imaginario social moderno - caracterizado en su línea dominante por el individualismo, la afirmación de la vida productiva-económica y familiar, un lenguaje de derechos y libertades, así como la aspiración hacia la igualdad y la inclusión (Taylor, 2006) - pueden, sin embargo, existir tensiones internas y, por ende, lucha; pero se trata de una lucha que en última instancia se juega a un nivel moral-identitario. Taylor figura, junto a la teoría crítica, como una de las principales influencias del sociólogo alemán Hartmut Rosa. En su último libro, Rosa $(2016)^{8}$ lanza en esta línea el proyecto de una sociología de la vida buena (eine Soziologie des guten Lebens) al tiempo que propone como solución al

Este libro acaba de ser editado en español por Katz Editores (2019) con traducción de Alexis Gros. 
problema moderno de la aceleración el establecimiento de vínculos de resonancia entre seres humanos y entre estos, y la naturaleza que los rodea.

Por último, cabe dedicar en este artículo algunas palabras a la obra de Pierre Bourdieu por el gran influjo que sus herramientas conceptuales e interpretaciones han tenido sobre la reflexión social del presente siglo. Su nombre, ya conocido en círculos académicos desde los años sesenta, pasó a liderar la vida intelectual francesa luego de la muerte de Foucault en 1984. En realidad, el pensamiento de Bourdieu mismo cabe presentarlo como una síntesis de muchas corrientes y conceptos clásicos aquí revisados, como la idea de relaciones sociales objetivo-económicas en Marx, la reproducción de las estructuras sociales en Durkheim o la teoría de la dominación en Weber, pero también el segundo Wittgenstein (el de las Investigaciones Filosóficas), MerleauPonty y otros autores aparecen contribuyendo a su sociología. No fueron solo sus innovaciones teóricas, entre las que figuran las nociones de habitus, capital o campo, sino por sobre todo sus investigaciones empíricas aplicadas a un gran número de fenómenos sociales - desde el mercado laboral hasta la escuela, pasando por los medios de comunicación - las que le granjearon a Bourdieu una gran reputación intelectual, tal como lo reconoce Daniel Gaxie en su entrevista (Basaure \& Montero, 2018).

Como notaba Mike Savage, para Bourdieu cada individuo no está solo definido por su pertenencia a una clase social y con su concomitante capital económico, sino que también por una serie de otros capitales: social, cultural (o informacional) y simbólico. Al llevar a cabo el ser humano su práctica diaria dentro de los diversos campos del quehacer moderno -económico, político, artístico, etcétera-, tomando en cuenta las relaciones sociales que allí se generan y la posición que dentro de dichos campos la persona ocupa (en particular, atendiendo a la distinción dominado/dominador), este va desarrollando ciertas disposiciones de percepción y acción, un sentido práctico, intuitivo y encarnado que lo orienta. El conjunto de estas disposiciones es lo que Bourdieu llama habitus y pueden servir inadvertidamente para cohesionar, legitimar y reproducir las formas sociales existentes de dominación. Al igual que Charles Taylor, Bourdieu concede una gran importancia a este nivel de comprensión implícita o encarnada que sustenta 
la vida social. Ambos autores comparten la motivación de superar una teoría intelectualista de la acción y mencionan a Hegel en este sentido como un antecedente importante.

Yo creo que todos aquellos que utilizaron este viejo concepto [habitus] u otros similares antes de mí, desde el ethos de Hegel, pasando por el Habitualität de Husserl, hasta el hexis de Mauss, estuvieron inspirados (tal vez sin saberlo) por una intención teórica emparentada con la mía, que es la de escapar de la filosofía del sujeto sin dejar de tomar en cuenta al agente, así como de la filosofía de la estructura pero sin olvidar los efectos que ésta ejerce sobre y a través del agente. (Bourdieu \& Wacquant, 2005, p. 162).

La superación de la dicotomía sujeto/estructura es evidente si prestamos atención al modo cómo Bourdieu explica el vínculo que existe entre habitus y campo, y entre las disposiciones del agente y las relaciones objetivas con que este agente se encuentra en el mundo social que habita. Se trata de un vínculo íntimo tanto de mutuo condicionamiento como de construcción cognitiva, donde no es posible distinguir netamente entre un sujeto y un objeto como sustancias heterogéneas que solo se tocan indirectamente en el sentido de la filosofía postcartesiana. "Siendo el habitus lo social encarnado, se encuentra 'en casa' en el campo que habita, lo percibe dotado de significado e interés inmediatos" (Bourdieu \& Wacquant, 2005, p. 169). La influencia de la fenomenología de Husserl, Heidegger y MerleauPonty es aquí notoria. Las crisis sociales, por el otro lado, pueden ser entendidas como momentos donde el ajuste entre habitus y campo se rompe, al punto que las personas no entienden o no saben cómo actuar frente a ciertas situaciones. Además, los campos son espacios de disputa entre fuerzas sociales, ya sea por conservar o transformar los capitales. En efecto, a pesar de su cohesión interna, el concepto bourdieusiano de campo alude a un aspecto dinámico de la realidad, que admite el conflicto.

El campo es escenario de relaciones de fuerza y de luchas encaminadas a transformarlas y, por consiguiente, el sitio de un cambio permanente. La coherencia que puede observarse en un estado dado del campo, su aparente orientación hacia una función única (por ejemplo, en el caso de las Grandes Escuelas en Francia, la reproducción de la estructura del campo del poder), es resultado del 
conflicto y la competencia, mas no de una suerte de autodesarrollo inmanente de la estructura. (Bourdieu \& Wacquant, 1995, p. 69).

Muchos de los entrevistados incluidos en el libro que da la ocasión al presente artículo reconocen una deuda con este pensador francés, entre ellos, Mike Savage, Michèle Lamont, Jamie Peck, Daniel Gaxie y Vincent de Gaulejac. No obstante lo anterior, algunos de estos, como es el caso de Lamont (1992), formularon conocidas críticas a las teorías bourdieusianas de capital cultural y habitus por ignorar el estatus moral de las personas, así como las diferencias nacionales, por ejemplo, entre las culturas de clase francesa y estadounidense. Pero esto solo confirma que el influjo de Bourdieu sigue siendo abrumador para la investigación y la teoría social producida en el siglo XXI.

En el presente artículo intentamos repasar algunos de los principales hitos en la teoría moderna del conflicto y la cohesión social, estableciendo líneas de continuidad entre planteamientos clásicos y contemporáneos, con ocasión de la aparición del libro Investigación y teoría crítica para la sociedad actual, el que ofrece una panorámica sobre el modo como las ciencias sociales están pensando estos fenómenos hoy en día. La ausencia de una definición operativa de conflicto y cohesión dentro de este trabajo responde al objetivo que nos hemos propuesto y que consistió, precisamente, en demostrar el modo heterogéneo en que dichas categorías han sido comprendidas, teorizadas y valoradas dentro de las tradiciones intelectuales modernas occidentales.

\section{Referencias}

Adorno, T. \& Horkheimer, M. (1998). Dialéctica de la Ilustración. Fragmentos filosóficos. Madrid: Trotta.

Althusser, L. (1978). The crisis of marxism. Marxism Today, 215-227.

Basaure, M. \& Montero, D. (Eds.). (2018). Investigación y teoría crítica para la sociedad actual. Barcelona: Anthropos.

Bourdieu, P. \& Wacquant, L. (1995). Respuestas. Por una antropología reflexiva. México D.F.: Grijalbo.

Bourdieu, P. \& Wacquant, L. (2005). Una invitación a la sociología reflexiva. Buenos Aires: Siglo XXI.

Coser, L. (1956). The functions of social conflict. Nueva York: The Free Press. 
Coser, L. (1967). Continuities in the study of social conflict. Nueva York: The Free Press.

Dahrendorf, R. (1959). Class and class conflict in industrial society. Stanford: Stanford University Press.

Dahrendorf, R. (1968). Essays in the theory of society. Stanford: Stanford University Press.

Durkheim, E. (2012). La división del trabajo social. Madrid: Biblioteca Nueva.

Engels, F. (2015). Prólogo. En K. Marx (autor), 18 brumario de Luis Bonaparte. Madrid: Alianza.

Foucault, M. (1980). Power/Knowledge: Selected interviews and other writings, 1972-1977. Nueva York: Random House.

Foucault, M. (1999). Estética, ética y hermenéutica. Barcelona: Paidós.

Gramsci, A. (2013). Antología. Madrid: Akal.

Habermas, J. (2010). Teoría de la acción comunicativa. Madrid: Trotta.

Hegel, G. W. F. (1999). Principio de la filosofía del derecho. Barcelona: Edhasa.

Hobbes, T. (1992). Leviatán. Buenos Aires: Fondo de Cultura Económica.

Honneth, A. (1997). La lucha por el reconocimiento. Por una gramática moral de los conflictos sociales. Barcelona: Crítica.

Lamont, M. (1992). Money, morals and manners. The culture of the French and the American upper middle class. Chicago: The University of Chicago Press.

Locke, J. (1990). Segundo tratado sobre el gobierno civil. Madrid: Alianza. Maquiavelo, N. (2003). The discourses. Londres: Penguin.

Marx, K. (1981). Contribución a la crítica de la economía política. México D.F.: Siglo XXI.

Marx, K. \& Engels, F. (1998). Manifiesto comunista. Madrid: Debate.

Marx, K. \& Engels, F. (2014). La ideología alemana. Madrid: Akal.

Merton, R. (1964). Teoría y estructura sociales. México D.F.: Fondo de Cultura Económica.

Michels, R. (2008). Los partidos políticos. Un estudio sociológico de las tendencias oligárquicas de la democracia moderna. Buenos Aires: Amorrortu Editores.

Mills, C. W. (1956). The power elite. Nueva York: Oxford University Press. 
Mills, C. W. (1959). The sociological imagination. Nueva York: Oxford University Press.

Montero, D. (2016). El concepto de democracia en el pensamiento político de Charles Taylor. Persona y Sociedad, 30(2), 57-76.

Mouffe, C. (1999). El retorno de lo político. Comunidad, ciudadanía, pluralismo, democracia radical. Barcelona: Paidós.

Parsons, T. (1968). La estructura de la acción social. Madrid: Ediciones Guadarrama.

Rosa, H. (2005). Beschleunigung: Die Veränderung der Zeitstrukturen in der Moderne. Frankfurt am Main: Suhrkamp.

Rosa, H. (2016). Resonanz: Eine Soziologie der Weltbeziehung. Berlín: Suhrkamp.

Rousseau, J. (1992). El contrato social. Madrid: Edaf.

Schumpeter, J. (2015). Capitalismo, socialismo y democracia. Barcelona: Página Indómita.

Simmel, G. (2010). El conflicto. Sociología del antagonismo. Madrid: Sequitur.

Taylor, C. (1983). Hegel y la sociedad moderna. México D.F: Fondo de Cultura Económica.

Taylor, C. (1985). Legitimation crisis? En C. Taylor (Autor), Philosophy and the Human Sciences (Vol. 2, Philosophical Papers, pp. 248-288). Cambridge: Cambridge University Press.

Taylor, C. (2006). Imaginarios sociales modernos. Barcelona: Paidós.

Taylor, M. (1987). The possibility of cooperation. Cambridge: Cambridge University Press.

Weber, M. (1998). La ética protestante y el espíritu del capitalismo. Barcelona: Península.

Weber, M. (2001). El político y el científico. Madrid: Alianza. 